\title{
B-type natriuretic peptide trumps other prognostic markers in patients assessed for coronary disease
}

\author{
Dipak Kotecha ${ }^{1,2^{*}}$ D, Marcus D. Flather ${ }^{3}$, Dan Atar ${ }^{4}$, Peter Collins ${ }^{5}$, John Pepper ${ }^{5}$, Elizabeth Jenkins ${ }^{6}$,
} Christopher M. Reid ${ }^{2,7}$, David Eccleston ${ }^{2}$ and on behalf of the Alternative Risk Markers in Coronary Artery Disease (ARM-CAD) Study

\begin{abstract}
Background: Risk prediction for patients with suspected coronary artery disease is complex due to the common occurrence of prior cardiovascular disease and extensive risk modification in primary care. Numerous markers have the potential to predict prognosis and guide management, but we currently lack robust 'real-world' evidence for their use.

Methods: Prospective, multicentre observational study of consecutive patients referred for elective coronary angiography. Clinicians were blinded to all risk assessments, consisting of conventional factors, radial artery pulse wave analysis, 5-minute heart rate variability, high-sensitivity C-reactive protein and B-type natriuretic peptide (BNP). Blinded, independent adjudication was performed for all-cause mortality and the composite of death, myocardial infarction or stroke, analysed with Cox proportional hazards regression.

Results: Five hundred twenty-two patients were assessed with median age 66 years and 21\% prior revascularization. Median baseline left ventricular ejection fraction was $64 \%$, and $62 \%$ had $\geq 50 \%$ stenosis on angiography. During 5.0 years median follow-up, 30\% underwent percutaneous and 16\% surgical revascularization. In multivariate analysis, only age and BNP were independently associated with outcomes. The adjusted hazard ratio per log unit increase in BNP was 2.15 for mortality $(95 \% \mathrm{Cl} 1.45-3.19 ; p=0.0001)$ and 1.27 for composite events $(1.04-1.54 ; p=0.018)$. Patients with baseline BNP > $100 \mathrm{pg} / \mathrm{mL}$ had substantially higher mortality and composite events (20.9\% and 32.2\%) than those with BNP $\leq 100 \mathrm{pg} / \mathrm{mL}$ (5.6\% and 15.5\%). BNP improved both classification and discrimination of outcomes $(p \leq 0.003)$, regardless of left ventricular systolic function. Conversely, high-sensitivity C-reactive protein, pulse wave analysis and heart rate variability were unrelated to prognosis at 5 years after risk modification and treatment of coronary disease.

Conclusions: Conventional risk factors and other markers of arterial compliance, inflammation and autonomic function have limited value for prediction of outcomes in risk-modified patients assessed for coronary disease. BNP can independently identify patients with subtle impairment of cardiac function that might benefit from more intensive management.
\end{abstract}

Trial registration: Clinicaltrials.gov, NCT00403351 Registered on 22 November 2006

Keywords: Risk, Mortality, Coronary artery disease, Coronary angiography, B-type natriuretic peptide

\footnotetext{
* Correspondence: d.kotecha@bham.ac.uk

${ }^{1}$ Institute of Cardiovascular Sciences, University of Birmingham, Birmingham, UK

${ }^{2}$ Monash Centre of Cardiovascular Research and Education in Therapeutics,

School of Public Health and Preventive Medicine, Melbourne, Australia

Full list of author information is available at the end of the article
}

(c) The Author(s). 2019 Open Access This article is distributed under the terms of the Creative Commons Attribution 4.0 International License (http://creativecommons.org/licenses/by/4.0/), which permits unrestricted use, distribution, and reproduction in any medium, provided you give appropriate credit to the original author(s) and the source, provide a link to the Creative Commons license, and indicate if changes were made. The Creative Commons Public Domain Dedication waiver (http://creativecommons.org/publicdomain/zero/1.0/) applies to the data made available in this article, unless otherwise stated. 


\section{Introduction}

The prediction of adverse cardiovascular events and mortality is well described for patients without cardiovascular disease (CVD) [1, 2]. However, many patients have prior myocardial infarction (MI) or other CVD, invalidating standard risk scores such as Framingham. Further, patients have often received extensive primary and secondary prevention therapy (antiplatelet and antihypertensive therapy, lipid-lowering, smoking cessation and revascularization). Thus, conventional risk factors are often poorly associated with coronary artery disease (CAD) [3] or prognosis in those with established CVD $[4,5]$. This leaves limited scope for identifying patients at high risk that might benefit from more intensive management.

A number of different risk markers with potentially novel mechanisms have been proposed to complement clinical factors. B-type natriuretic peptide (BNP) assesses cardiac strain and function [6], but is rarely considered in clinical practice outside of heart failure assessment despite suggestive evidence of value in CAD patients [7]. Pulse wave technologies are a surrogate for vascular stiffness [8]; however, their value beyond standard blood pressure is uncertain. Heart rate variability (HRV) is a marker of autonomic function [9], but with unknown effectiveness for risk prediction [10]. High-sensitivity C-reactive protein (hs-CRP) is an effective marker of inflammation, but additional risk stratification has not been established [11].

The Alternative Risk Markers in Coronary Artery Disease (ARM-CAD) study was designed to provide an unbiased assessment of non-invasive markers in a 'real-world' population. A randomised trial would not have been ethical in this situation, so instead we employed numerous methods to reduce potential bias. Risk assessment was performed prior to angiography, clinicians were blinded to results to avoid any impact on treatment over the 5 years of follow-up, and outcomes were independently adjudicated. Our aim was to establish the clinical value of these risk markers by assessing their relationship with mortality and the composite of death, MI or stroke, both early and late after planned coronary angiography.

\section{Methods}

\section{Patient population}

Patients referred for elective coronary angiography were recruited in three centres in Melbourne, Australia, with consecutive enrolment 2006-2008 following written informed consent. The only exclusion criteria were a precipitating acute coronary syndrome (ACS) or prior heart transplantation. All patients were assessed prospectively, prior to angiography, with the cardiologists blinded to all risk assessments throughout the follow-up period.
The study was approved by local ethics committees, conducted according to the Declaration of Helsinki, and prospectively registered (https://clinicaltrials.gov/ct2/ show/NCT00403351).

\section{Risk markers}

Conventional risk factors were determined at patient study visits and with blood testing, in addition to careful review and confirmation using electronic health records and medical notes. Information on participants was collated with a bespoke electronic case report system separate from any clinical databases. Definitions on risk markers have previously been published [3, 8, 9], and further detail is presented in Additional file 1: Appendix 1.

\section{Coronary angiography}

Coronary angiography was performed by experienced operators using standardised procedures. Patients were classified as normal, minor plaque or the number of coronary artery territories with a luminal stenosis $\geq 50 \%$ in main vessels or major tributaries. To ensure consistency, the angiographic core laboratory randomly evaluated angiograms during the study and at each centre, with two experienced, blinded operators.

\section{Outcomes}

All-cause mortality and the composite of death, MI or stroke were independently adjudicated by clinicians blinded to patient details. Confirmation of events required documentary evidence supporting the diagnosis (for example, a death certificate, cardiologist or neurologist diagnosis, or troponin-positive ACS). We also collected detailed information about percutaneous coronary intervention (PCI), coronary artery bypass grafting (CABG) and other events during follow-up by reviewing electronic and physical notes, discussion with the patients' cardiologist or general practitioner, and yearly telephone interviews with participants.

\section{Statistics}

Values are presented as median \pm interquartile range (IQR; 25th to 75th centiles) or percentage. Risk factor variables were assessed by tertile for Kaplan-Meier analysis and continuously in Cox proportional hazard regression. Where variables demonstrated a skewed distribution (for example, BNP, hs-CRP, HRV power and risk scores), these were normalised for statistical analysis by taking the natural logarithm. We pre-specified cut-points for a number of variables of interest: BNP $100 \mathrm{pg} / \mathrm{mL}$, central augmentation pressure $24 \mathrm{mmHg}$, central pulse pressure $50 \mathrm{mmHg}$, low-frequency $\mathrm{HRV}$ $250 \mathrm{~ms}^{2}$ and hs-CRP $3 \mathrm{mg} / \mathrm{L}$. Group comparisons were assessed with the Kruskal-Wallis non-parametric 
analysis of variance test, with $p$ value adjustment for multiple comparisons. Kaplan-Meier groups were compared with the log-rank test of equality for binary variables and a log-rank trend test for tertiles.

The main multivariate Cox model consisted of age, gender, current smoking, systolic and diastolic blood pressure, use of renin-angiotensin-aldosterone antagonists, total cholesterol, statin therapy, diabetes, prior MI, $\mathrm{BNP}$, the extent of angiographic CAD, the presence of left ventricular systolic dysfunction and revascularization during follow-up. Additional risk markers were then added separately. A time-varying interaction term was also included, and results are presented as hazard ratios (HR) with associated 95\% confidence intervals (CI). We also performed stepwise inclusion at a threshold of $p<$ 0.2 of a much broader range of variables (including renal function, body mass index and other medical therapy); this had no appreciable effect on results. Interactions were assessed with likelihood ratio testing, and the proportional hazards assumption was confirmed using Schoenfeld residuals. To understand the impact of risk factor modification over time, analyses were also performed at a 1-year landmark time point.

Harrell's C-statistic (the area under the receiver operator curve) and Somers' D-statistic were calculated in the final model with and without BNP to assess its additive value. These statistics were compared using published methods [12], with randomly generated derivation and validation sets of equal size, stratified by age and left ventricular systolic dysfunction. To determine the discriminatory ability of baseline BNP, we calculated the net reclassification improvement and integrated discrimination improvement using logistic regression in a multivariate model adding $\mathrm{BNP}$ to conventional clinical risk predictors (age, male gender, family history of premature CVD, current smoking, prior MI, diabetes, blood pressure $\geq 140 / \geq 90 \mathrm{mmHg}$ or hypertensive therapy, total cholesterol $>5.2 \mathrm{mmol} / \mathrm{L}[200 \mathrm{mg} / \mathrm{dL}], \geq 50 \%$ stenosis on angiography and left ventricular ejection fraction [LVEF] $<50 \%$ ) [13]. To reflect the high event proportions, predicted risk of death cut-points were a priori selected at $20 \%, 30 \%$ and $40 \%$.

Post hoc analyses were performed to (1) exclude patients with atrial arrhythmias from central augmentation pressure and HRV Kaplan-Meier plots, (2) assess the impact of HRV in patients without revascularization, (3) identify any interaction of BNP with the severity of CAD and diastolic dysfunction, (4) exclude patients with entirely normal coronary angiography or those with left ventricular systolic dysfunction, and (5) evaluate the pre-specified $100 \mathrm{pg} / \mathrm{mL}$ cut-point of BNP.

A two-tailed $p$ value of $<0.05$ was considered statistically significant. Analyses used complete case data as the amount of missing data was small (no imputation performed). Statistical analysis was performed with Stata (version 14.2, StataCorp LP, TX, USA).

\section{Results}

The ARM-CAD longitudinal study population consists of 526 patients recruited prior to elective coronary angiography, with a median follow-up period of 5.0 years (IQR 3.5-6.0). Follow-up data were unavailable in four participants (0.8\%, Fig. 1).

\section{Baseline characteristics and associations}

Table 1 reports the baseline demographics for the study population, with median age 66 years (IQR 58-73) and LVEF 64\% (IQR 53-71\%). Prior to angiography, 394 patients $(75.5 \%)$ disclosed chest pain and 335 (64.2\%) some degree of dyspnoea. Twelve patients (2.3\%) had a history of a congestive heart failure episode. There was a broad range of BNP values which correlated with the degree of left ventricular systolic dysfunction, but not central pulse pressure (Additional file 1: Appendix 2). BNP was in the heart failure range $(>400 \mathrm{pg} / \mathrm{mL})$ in only $5.6 \%$.

\section{Coronary disease, revascularization and risk reduction}

The majority of patients (80\%) had some degree of atheroma on angiography at baseline and $62 \%$ had one or more luminal stenoses $\geq 50 \%$. Over the 5 years of follow-up, $15.6 \%$ underwent CABG and $29.9 \%$ of participants had at least one PCI procedure (drug-eluting stents used in 55\%). There were similar total numbers of revascularization procedures in those with $\mathrm{BNP} \leq 100$ $\mathrm{pg} / \mathrm{mL}$ at baseline and $>100 \mathrm{pg} / \mathrm{mL}(p=0.69$; see Fig. 1 for breakdown and Additional file 1: Appendix 3 for Kaplan-Meier curves). Patients were actively treated with medical therapy even prior to angiography (Additional file 1: Appendix 4) by highly involved secondary care physicians - the mean number of hospital visits per person was 1.3 in the first 12 months following angiography (standard deviation 0.6 visits).

\section{Adjudicated outcomes}

Forty-seven participants (9.0\%) died during follow-up. Cardiovascular causes accounted for 23 deaths (49\%), of which 18 (38\%) were due to cardiac causes and 5 (11\%) from stroke. Adjudicated death, MI or stroke occurred in 100 participants (19.2\%; 109 total events). Kaplan-Meier univariate analysis confirmed a significant trend across tertiles of BNP both at the 1-year landmark point and at median 5 years of follow-up (Fig. 2a). Hs-CRP (Fig. 2b) and central augmentation pressure (Fig. 2c) were unrelated to outcomes at either time point, whereas the ratio of low/high-frequency HRV power was significant at 1 year but not at 5 years (Fig. 2d). Conversely, both Framingham risk (Fig. 2e) and the extent of CAD on angiography (Fig. 2f) were 


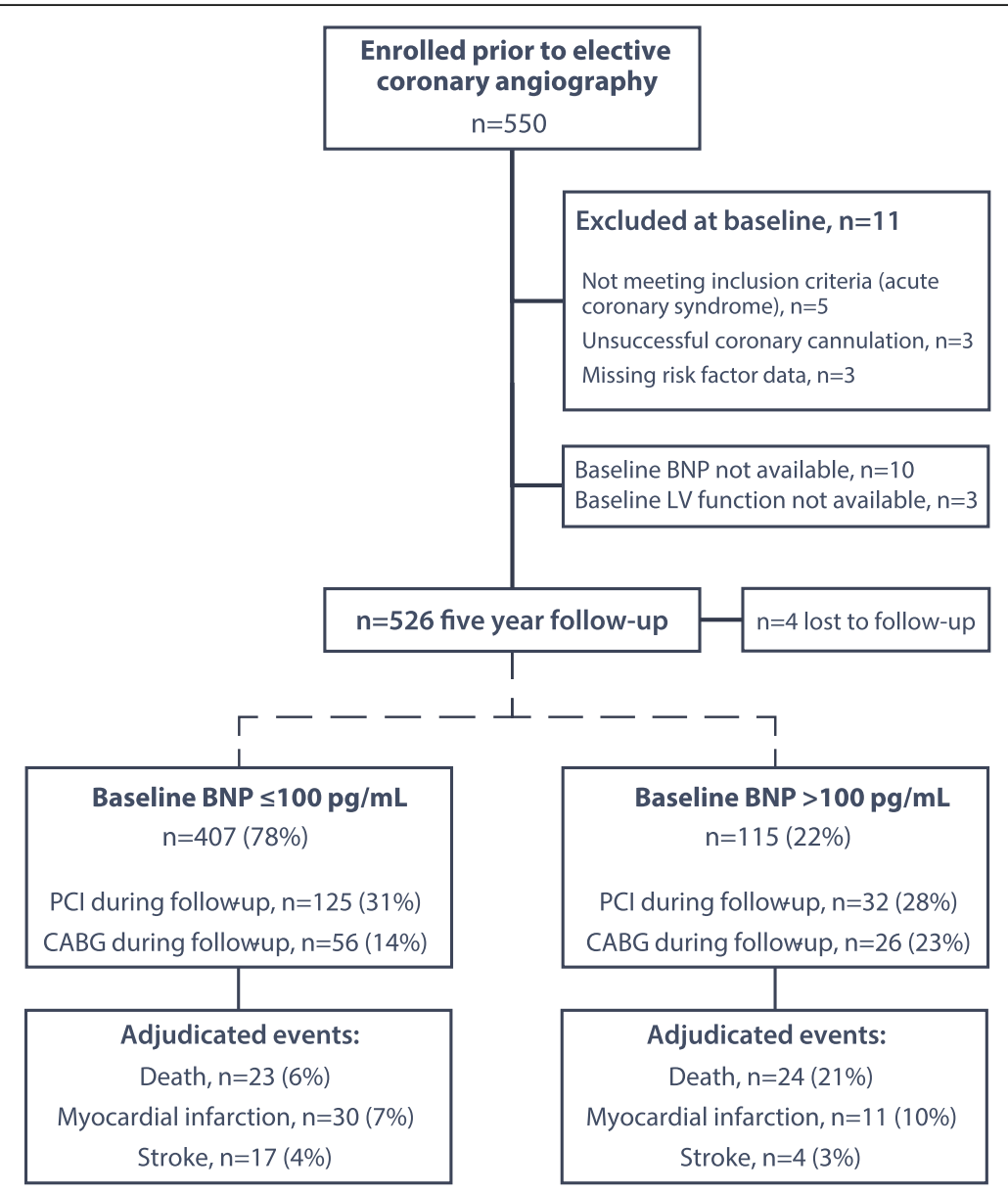

Fig. 1 Flowchart for the ARM-CAD study. Includes independently adjudicated events subdivided by baseline BNP level. BNP, B-type natriuretic peptide; $\mathrm{PCl}$, percutaneous coronary intervention; $\mathrm{CABG}$, coronary artery bypass grafting ( $\mathrm{PCl}$ and $\mathrm{CABG}$ are not mutually exclusive)

non-significant at 1 year, but were statistically associated with adverse outcomes by the end of follow-up. Neither Framingham nor SCORE had value beyond age alone (Additional file 1: Appendix 5).

Across all multivariate models, the only individual baseline risk markers associated with adverse outcomes were age and BNP (Table 2 and Additional file 1: Appendix 6). For all-cause mortality, the HR for age per 10-year increment was 2.29 (95\% CI 1.51-3.48; $p=0.0001)$ after adjustment for conventional risk factors, medical therapy, the extent of angiographic CAD and overt left ventricular systolic dysfunction. Per log unit increase in BNP, the adjusted HR was 2.15 (95\% CI 1.45-3.19; $p=0.0001$ ), with no interaction with the presence of left ventricular systolic dysfunction $\left(p_{\text {interaction }}=0.69\right)$. Similar findings were observed for death, MI or stroke. Both the Framingham and SCORE composite risk tools were associated with adverse outcomes in multivariate analysis, with no interaction according to baseline cardiovascular disease (all $p_{\text {interactions }} \geq$ 0.50; Table 2). A revascularization procedure during follow-up was associated with a significant reduction in the risk of death, with an adjusted HR of 0.45 (95\% CI 0.23-0.87; $p=0.018$ ).

Patients with baseline BNP > $100 \mathrm{pg} / \mathrm{mL}$ had substantially more adverse outcomes. Deaths occurred in 24/115 (20.9\%) versus 23/407 (5.7\%) in patients with BNP $\leq 100$ $\mathrm{pg} / \mathrm{mL}$, with an adjusted HR of 4.49 (95\% CI 2.09-9.62; $p$ $=0.0001$ ) and no interactions in subgroup analysis (Additional file 1: Appendix 6). Death, MI or stroke occurred in $37 / 115(32.2 \%)$ with $\mathrm{BNP}>100 \mathrm{pg} / \mathrm{mL}$ versus $63 / 407$ (15.5\%) with BNP $\leq 100 \mathrm{pg} / \mathrm{mL}$, with an adjusted HR of 1.95 (95\% CI 1.20-3.18; $p=0.007$ ). The Kaplan-Meier survival curves are presented in Fig. 3, with clear and early separation in patients with baseline BNP $>100 \mathrm{pg} / \mathrm{mL}$ for both outcomes. No other cut-points were of statistical relevance, including those for central augmentation pressure, central pulse pressure, low-frequency HRV power and hs-CRP (Additional file 1: Appendix 7). In sensitivity analyses, BNP $>100 \mathrm{pg} / \mathrm{mL}$ had the same association with composite outcomes after exclusion of patients with normal coronary angiography (adjusted HR 2.03, 95\% CI $1.23-3.34 ; p=0.006 ; n=420$ ) or exclusion of those with 
Table 1 Baseline characteristics

\begin{tabular}{|c|c|c|c|c|}
\hline \multirow[t]{2}{*}{ Characteristic } & \multirow{2}{*}{$\begin{array}{l}\text { All } \\
N=522 \\
\text { Median (IQR) or } \%\end{array}$} & \multirow{2}{*}{$\begin{array}{l}\text { BNP } \leq 100 \mathrm{pg} / \mathrm{mL} \\
N=407 \\
\text { Median (IQR) or } \%\end{array}$} & $\begin{array}{l}\mathrm{BNP}>100 \mathrm{pg} / \mathrm{mL} \\
\mathrm{N}=115\end{array}$ & \multirow[t]{2}{*}{$p$ value } \\
\hline & & & Median (IQR) or \% & \\
\hline Age, years & $66(58-73)$ & $64(56-71)$ & $70(65-76)$ & $<0.0001$ \\
\hline Women, \% & $32.8 \%$ & $33.4 \%$ & $30.4 \%$ & NS \\
\hline Current smoker, \% & $16.1 \%$ & $17.2 \%$ & $12.2 \%$ & NS \\
\hline Prior myocardial infarction, $\%$ & $22.2 \%$ & $20.9 \%$ & $27.0 \%$ & NS \\
\hline Prior revascularization, \% & $20.9 \%$ & $19.9 \%$ & $24.3 \%$ & NS \\
\hline Diabetes mellitus, \% & $22.0 \%$ & $23.3 \%$ & $17.4 \%$ & NS \\
\hline Left ventricular ejection fraction, \%* & $64(53-71)$ & $65(58-72)$ & $53(39-67)$ & $<0.0001$ \\
\hline Left ventricular systolic dysfunction, $\%$ & $19.0 \%$ & $13.0 \%$ & $40.0 \%$ & $<0.0001$ \\
\hline Body mass index, $\mathrm{kg} / \mathrm{m}^{2}$ & $28(25-31)$ & $28(26-31)$ & $27(25-31)$ & NS \\
\hline Systolic blood pressure, $\mathrm{mmHg}$ & $140(129-156)$ & 139 (129-153) & $145(131-161)$ & 0.019 \\
\hline Diastolic blood pressure, $\mathrm{mmHg}$ & $79(72-86)$ & $79(73-86)$ & $77(69-85)$ & NS \\
\hline Central augmentation pressure, $\mathrm{mmHg}^{\dagger}$ & $16(9-23)$ & $15(9-22)$ & $20(10-27)$ & 0.003 \\
\hline$\geq 24 \mathrm{mmHg}$ & $23.5 \%$ & $18.7 \%$ & $40.7 \%$ & 0.0002 \\
\hline Central pulse pressure, $\mathrm{mmHg}^{+}$ & $50(39-63)$ & $49(39-61)$ & $56(42-73)$ & 0.001 \\
\hline$\geq 50 \mathrm{mmHg}$ & $52.1 \%$ & $49.1 \%$ & $62.8 \%$ & 0.13 \\
\hline Total cholesterol, mmol/L & $4.5(3.8-5.2)$ & $4.5(3.9-5.4)$ & $4.1(3.5-4.7)$ & $<0.0001$ \\
\hline High-density lipoprotein cholesterol, mmol/L & $1.2(1.0-1.4)$ & $1.2(1.0-1.4)$ & $1.2(1.0-1.5)$ & NS \\
\hline Estimated glomerular filtration rate, $\mathrm{mL} / \mathrm{min}$ & $82(68-97)$ & $85(69-98)$ & $78(60-93)$ & 0.002 \\
\hline Low-frequency heart rate variability, $\mathrm{ms}^{2} \neq$ & $211(72-470)$ & $213(85-446)$ & $191(27-1017)$ & NS \\
\hline$>250 \mathrm{~ms}^{2}$ & $56.5 \%$ & $57.4 \%$ & $52.7 \%$ & NS \\
\hline Total power heart rate variability, $\mathrm{ms}^{2} \neq$ & $830(323-1954)$ & $766(360-1764)$ & $1101(198-3150)$ & NS \\
\hline High-sensitivity C-reactive protein, mg/L & $1.9(0.9-4.0)$ & $1.9(0.8-3.9)$ & $2.1(1.0-4.5)$ & NS \\
\hline$>3 \mathrm{mg} / \mathrm{L}$ & $32.4 \%$ & $31.9 \%$ & $34.2 \%$ & NS \\
\hline B-type natriuretic peptide, $\mathrm{pg} / \mathrm{mL}$ & $40(15-90)$ & $27(12-53)$ & $188(137-413)$ & - \\
\hline$>100 \mathrm{pg} / \mathrm{mL}$ & $22.0 \%$ & & & \\
\hline$>400 \mathrm{pg} / \mathrm{mL}$ & $5.6 \%$ & & & \\
\hline Framingham 10-year risk, \% & $11(8-20)$ & $11(7-20)$ & $13(8-20)$ & NS \\
\hline SCORE 10-year risk, \% & $9(4-17)$ & $8(3-16)$ & $12(7-22)$ & $<0.0001$ \\
\hline
\end{tabular}

NS not significant (adjusted for multiple comparisons)

*Based on the subset of patients with echocardiography prior to angiography $(n=295)$

${ }^{\dagger} n=8$ missing

${ }^{\ddagger}$ Participants with a stable ECG signal over 5 min $(n=464)$

$n=1$ missing

any degree of left ventricular systolic dysfunction (adjusted HR $2.55,95 \%$ CI $1.40-4.61 ; p=0.002 ; n=423)$.

\section{Discrimination value of BNP}

The addition of BNP as a continuous variable increased both Harrell's $C$ and Somers' D statistics in multivariate models $(t=4.0, p<0.001$ and $t=5.9, p<0.001$ respectively for all-cause mortality). The C-statistic in the random validation subset was 0.91 with BNP and 0.69 without. When added to conventional risk predictors, BNP $>100$ versus $\leq 100 \mathrm{pg} / \mathrm{mL}$ improved the classification of death (net improvement in 10 cases from 47 deaths, $21.3 \%$ ), with minimal change in the classification of survivors (net improvement in 2 cases from 475 survivors, 0.4\%; Additional file 1: Appendix 8). Both net reclassification improvement (NRI) and integrated discrimination improvement (IDI) analyses were highly significant (NRI $0.281, p=0.003$; IDI $0.038, p=0.0007$ ). Figure 4 displays a contour prediction map combining age and BNP to assess the clinical risk of 5-year mortality.

A plain English summary of results for patients and carers is presented in Additional file 2. 


\section{A Tertiles of B-type natriuretic peptide}

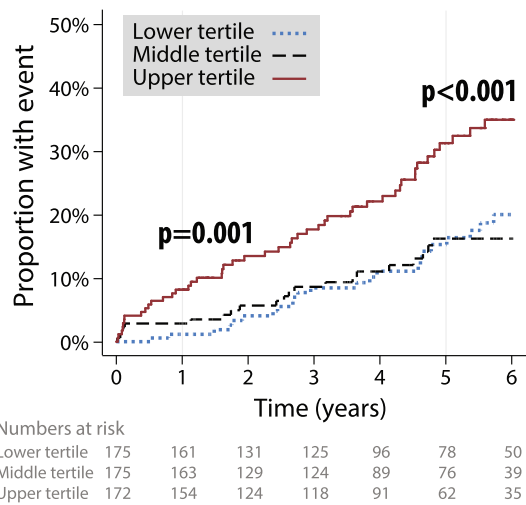

\section{Tertiles of central augmentation} pressure (pulse wave analysis) *

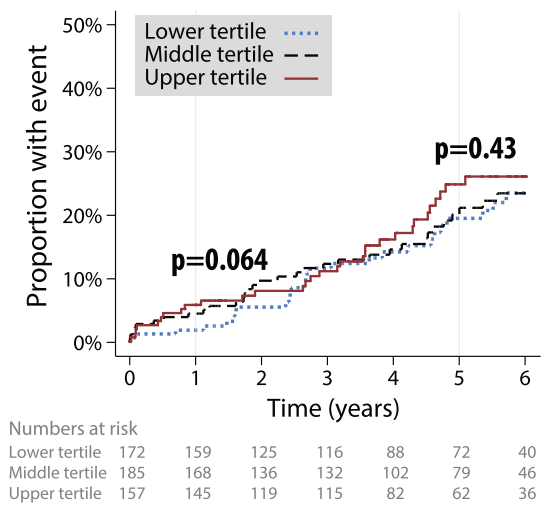

\section{E Tertiles of 10-year Framingham coronary heart disease risk}

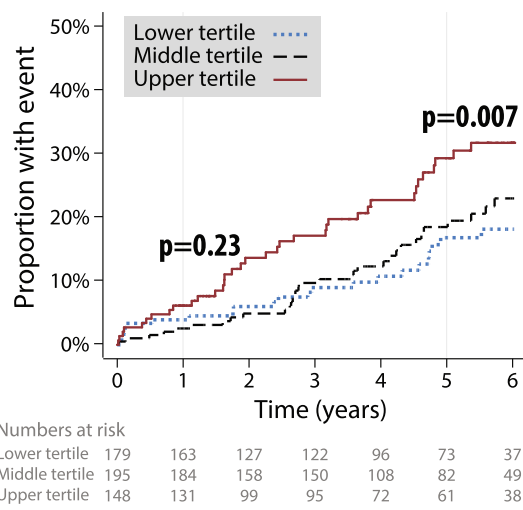

\section{B Tertiles of high-sensitivity} C-reactive protein

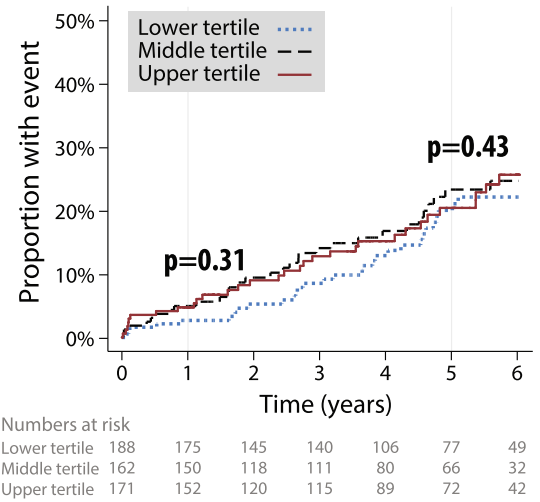

\section{Tertiles of low/high frequency power ratio (heart rate variability) ${ }^{*}$}

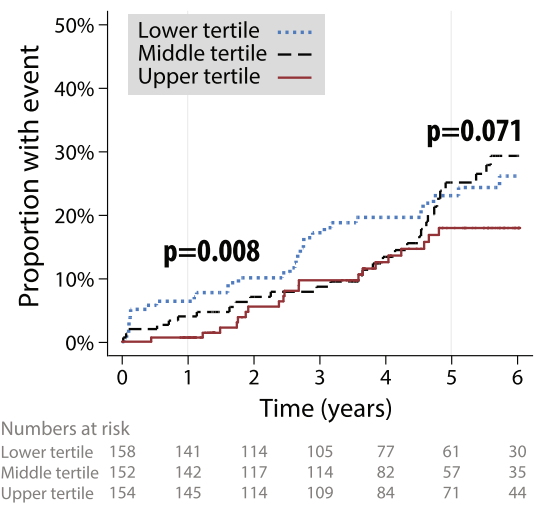

\section{F Coronary artery disease on angiography}

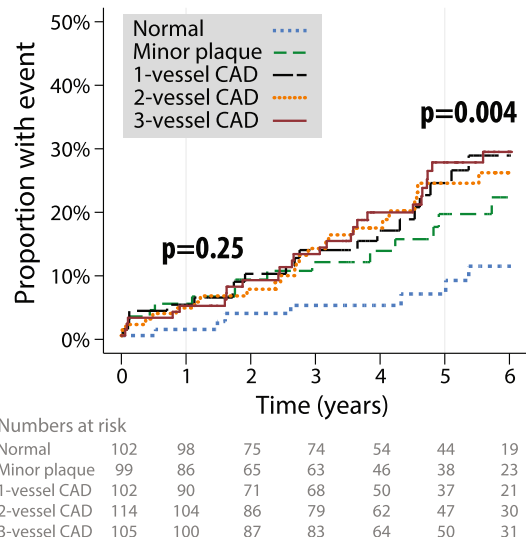

Fig. 2 Kaplan Meier curves for death, myocardial infarction or stroke. Apart from coronary angiogram results, clinicians remained blinded to all other baseline risk markers. $p$ values are a chi-squared log-rank test for trend performed at a landmark censoring of 1 year and at the median 5-year followup. Corresponding $p$ values for all-cause mortality alone at 5-year follow-up are a BNP $p=0.001$, $\mathbf{b}$ hs-CRP $p=0.27$, $\mathbf{c}$ central augmentation pressure $p=0.38$, d low/high-frequency HRV $p=0.30$, e Framingham risk $p=0.026$, $\mathbf{f}$ Angiographic coronary disease $p=0.09$. *Post hoc exclusion of patients with atrial arrhythmias at baseline or follow-up had no impact on results. +Post hoc exclusion of patients with any revascularization resulted in $p_{\text {trend }}=$ 0.029 for death, Ml or CVA at 5-year follow-up, and 0.18 for mortality alone. CAD, coronary artery disease 
Table 2 Multivariate analysis

\begin{tabular}{|c|c|c|c|c|c|c|}
\hline & \multicolumn{3}{|c|}{ All-cause mortality } & \multicolumn{3}{|c|}{ Death, Ml or stroke } \\
\hline & $\mathrm{HR}$ & $95 \% \mathrm{Cl}$ & $p$ value & $\mathrm{HR}$ & $95 \% \mathrm{Cl}$ & $p$ value \\
\hline \multicolumn{7}{|l|}{ Main multivariate model* } \\
\hline Age (per 10 years) & 2.29 & $1.51-3.48$ & $<0.001$ & 1.63 & $1.24-2.13$ & $<0.001$ \\
\hline Male gender & 1.82 & $0.86-3.82$ & 0.12 & 1.91 & $1.10-3.33$ & 0.022 \\
\hline Prior myocardial infarction & 1.71 & $0.85-3.44$ & 0.13 & 1.60 & $0.98-2.61$ & 0.06 \\
\hline Diabetes & 1.13 & $0.55-2.32$ & 0.74 & 1.34 & $0.82-2.18$ & 0.24 \\
\hline Smoking & 1.39 & $0.63-3.10$ & 0.41 & 1.39 & $0.78-2.47$ & 0.26 \\
\hline Presence of impaired left ventricular function & 1.32 & $0.63-2.77$ & 0.46 & 1.22 & $0.72-2.08$ & 0.46 \\
\hline Extent of angiographic CAD (per vessel with $\geq 50 \%$ ) & 1.03 & $0.77-1.39$ & 0.84 & 0.90 & $0.72-1.13$ & 0.38 \\
\hline Revascularization & 0.45 & $0.23-0.87$ & 0.018 & 1.18 & $0.73-1.91$ & 0.49 \\
\hline Cholesterol (per $1 \mathrm{mmol} / \mathrm{L}$ ) & 1.09 & $0.79-1.49$ & 0.60 & 1.14 & $0.91-1.42$ & 0.26 \\
\hline Systolic blood pressure (per 1 mmHg) & 0.99 & $0.98-1.01$ & 0.36 & 0.99 & $0.98-1.01$ & 0.36 \\
\hline BNP (per log unit) & 2.15 & $1.45-3.19$ & $<0.001$ & 1.27 & $1.04-1.54$ & 0.018 \\
\hline \multicolumn{7}{|l|}{ Additional risk markers ${ }^{\dagger}$} \\
\hline \multicolumn{7}{|l|}{ Pulse wave analysis } \\
\hline Central augmentation pressure (per $1 \mathrm{mmHg}$ ) & 0.97 & $0.93-1.02$ & 0.27 & 1.00 & $0.97-1.04$ & 0.92 \\
\hline Central augmentation index (per 1\%) & 0.98 & $0.95-1.01$ & 0.26 & 1.00 & $0.98-1.02$ & 0.89 \\
\hline Central pulse pressure (per $1 \mathrm{mmHg}$ ) & 0.98 & $0.93-1.04$ & 0.59 & 1.00 & $0.96-1.04$ & 0.88 \\
\hline \multicolumn{7}{|l|}{ Heart rate variability } \\
\hline Standard deviation of RR intervals (per log ms) & 0.88 & $0.57-1.37$ & 0.58 & 0.91 & $0.67-1.26$ & 0.58 \\
\hline Low-frequency power (per $\log \mathrm{ms}^{2}$ ) & 0.97 & $0.81-1.15$ & 0.70 & 0.97 & $0.85-1.10$ & 0.59 \\
\hline Total frequency power (per log ms²) & 0.95 & $0.78-1.15$ & 0.58 & 0.95 & $0.82-1.09$ & 0.45 \\
\hline Low to high-frequency power ratio (per log unit) & 1.00 & $0.73-1.38$ & 0.99 & 0.96 & $0.78-1.18$ & 0.72 \\
\hline \multicolumn{7}{|l|}{ Other biomarkers } \\
\hline High-sensitivity C-reactive protein (per 1 mg/L) & 1.11 & $0.85-1.46$ & 0.43 & 1.00 & $0.84-1.20$ & 0.98 \\
\hline Estimated glomerular filtration rate (per $10 \mathrm{~mL} / \mathrm{min}$ ) & 0.94 & $0.81-1.09$ & 0.40 & 0.99 & $0.90-1.08$ & 0.76 \\
\hline \multicolumn{7}{|l|}{ Conventional risk scores ${ }^{\ddagger}$} \\
\hline Framingham 10-year risk (per log unit) & 1.69 & $1.19-2.41$ & 0.004 & 1.64 & $1.00-2.68$ & 0.049 \\
\hline SCORE 10-year risk (per log unit) & 1.41 & $1.14-1.74$ & 0.002 & 1.59 & $1.16-2.17$ & 0.004 \\
\hline
\end{tabular}

*Also adjusted for statin therapy, diastolic blood pressure and use of renin-angiotensin-aldosterone antagonists

${ }^{+}$Variables separately added to the main multivariate model. Age and BNP remained significantly associated with outcomes in all models

${ }^{\ddagger}$ Modified model that includes the risk score, prior MI, extent of angiographic CAD, impaired left ventricular function, BNP, use of renin-angiotensin-aldosterone

antagonists, use of statin therapy and revascularization on follow-up, but not the components of the risk score

$p_{\text {interaction }}$ for baseline cardiovascular disease $=0.76$ for all-cause mortality and 0.50 for death, $\mathrm{Ml}$ or stroke

$p_{\text {interaction }}$ for baseline cardiovascular disease $=0.96$ for all-cause mortality and 0.74 for death, $\mathrm{Ml}$ or stroke

\section{Discussion}

Our study extends the importance of BNP, a marker of myocardial dysfunction, to include adverse cardiovascular events and death in patients with suspected CAD, even at low elevation of BNP (suggestive of subtle cardiac impairment). The association of BNP with prognosis was independent of overt left ventricular systolic dysfunction, age and other risk factors and persisted despite effective primary and secondary risk factor modification and high rates of revascularisation over 5 years. On the contrary, other risk markers that focus on vascular pressure and arterial compliance (PWA), inflammatory responses (hs-CRP) and autonomic function (HRV) were not independent of risk modification. The strengths of the ARM-CAD study cohort were inclusion of unselected and consecutive patients (with results generalisable to routine clinical practice), blinding of risk assessment to clinicians, rigorous protocol-defined assessment and follow-up, low rates of loss to follow-up and independent adjudication of adverse outcomes.

\section{Cardiovascular risk assessment}

Risk scores like GRACE (Global Registry of Acute Coronary Events) for ACS patients [14] confirm that many of the original Framingham Heart Study risk factors may lose relevance in patients with prevalent CVD. In our 


\section{A BNP: All-cause mortality}

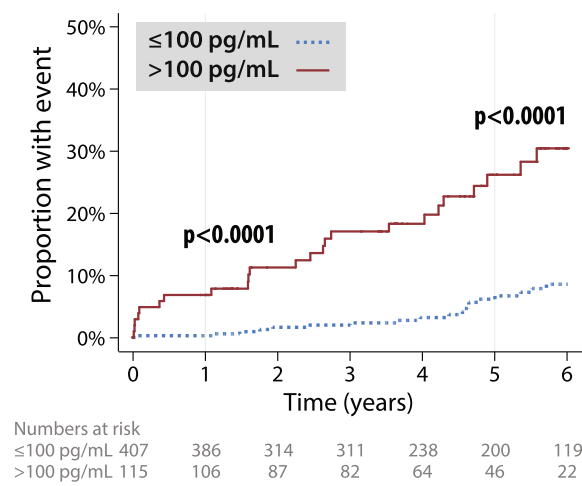

\section{B BNP: Death, Ml or stroke}

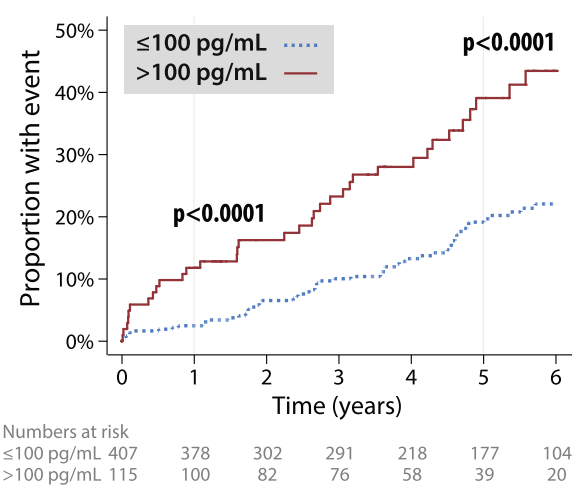

Fig. 3 Kaplan-Meier adverse event curves according to the pre-specified BNP cut-point of $100 \mathrm{pg} / \mathrm{mL}$ for a: all-cause mortality; and $\mathbf{b}$ : death, MI or stroke. BNP, B-type natriuretic peptide; MI, myocardial infarction

study, only age was independently associated with outcomes. This highlights the need to find alternative markers that can identify those patients at high residual risk despite risk factor management, or in those with existing disease.

\section{Pulse wave analysis}

Following two large outcome studies of patients free of major CVD $[15,16]$, derived aortic waveforms are now frequently used in research studies as surrogate outcome measures. Our analysis in comorbid patients, with nearly four times the number of events as a prior study [17], found no relationship between the arterial waveform and clinical outcomes. This may have been due to treatment of underlying risk factors and use of vasoactive medications, which are known to affect central pressures [18].

\section{Heart rate variability}

Low HRV is associated with an increased risk of incident events in those without CVD [19], can discriminate patients with a complicated course following MI [20, 21] and is a prognostic marker in heart failure [22]. Our prior results confirmed that reduction in HRV was an independent predictor of the presence and severity of angiographic CAD [9]. In the current analysis, we identified a significant relationship with crude events at the

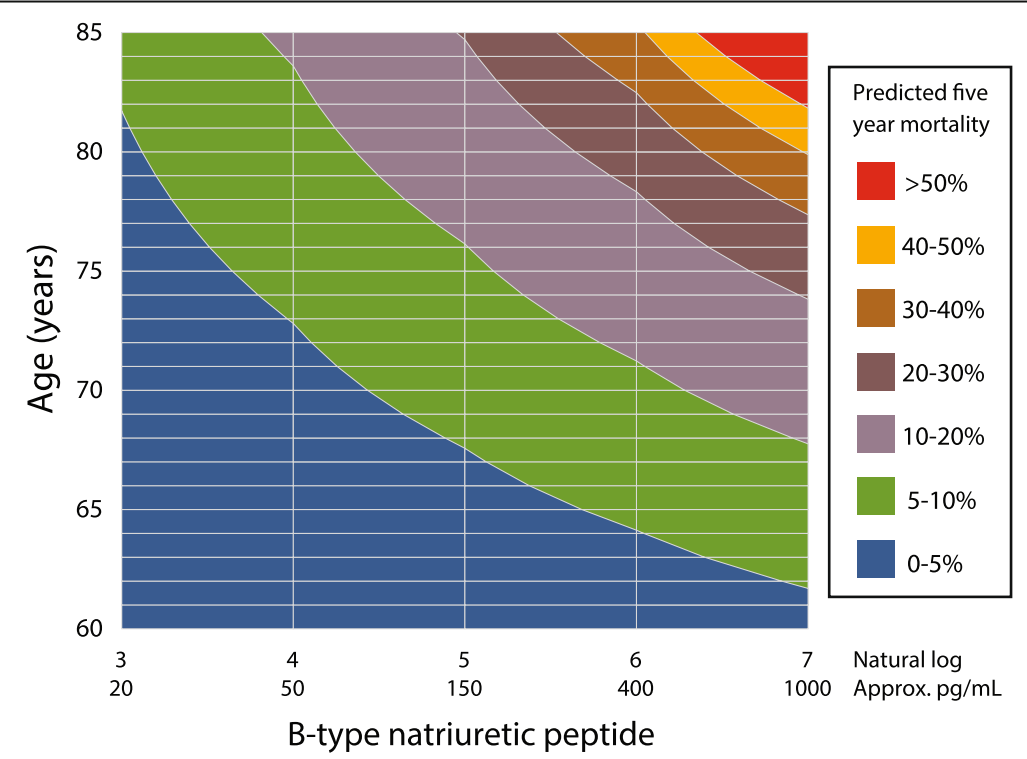

Fig. 4 Risk contour map for adjusted predicted mortality according to age and BNP. Example: 75 -year-old patient with a BNP of $25 \mathrm{pg} / \mathrm{mL}$ has a predicted 5 -year mortality of 0-5\%, compared to $10-20 \%$ in a patient of the same age with a BNP of $200 \mathrm{pg} / \mathrm{mL}$. Note that risk estimates are based on the ARM-CAD cohort of patients with extensive modification of risk factors and concomitant disease, revascularization as required, and highly involved secondary care physicians 
landmark 1-year point, but no association at final follow-up, nor in multivariate analysis. This may have been due to the lack of power (however in this case, the clinical value is likely to be small), that HRV is not entirely independent of conventional factors, or that revascularisation may play a role [10]. When we excluded patients with any prior revascularisation, we identified a statistically significant trend for tertiles of the ratio of low/high-frequency HRV power at 5 years. However, this should be considered hypothesis-generating due to the smaller sample size $(n=223)$ and post hoc assessment. It is also important to note that HRV acquisition was unsuccessful in $11 \%$ of our cohort, predominantly due to rhythm abnormalities [9].

\section{Biomarkers}

hs-CRP has been extensively studied as a marker of inflammation, but has relatively poor ability to alter clinical management [11]. In our blinded assessment of a cohort with extensive risk management, we found no relationship with long-term outcomes.

In contrast, BNP was independent of other risk factors and was the only individual marker (aside from age) to be associated with clinical outcomes in multivariate analysis. BNP is produced by the myocardium in response to wall stress and acts to reduce venous return to the heart through actions on the vascular endothelium (smooth muscle relaxation and increased endothelial permeability), the kidneys (stimulation of diuresis and natriuresis) and suppression of reflex sympathetic activation [23, 24]. In patients with CAD or ACS, BNP is a powerful predictor of death and other clinical events [25-27], with analogous findings for NT-proBNP [28, 29]. Of interest, BNP is not associated with clinical events in healthy patients with normal echocardiograms and the absence of cardiovascular risk factors [30]. The mechanism for a rise in BNP in patients with coronary atherosclerosis but the absence of myocardial necrosis is presumably transient left ventricular systolic dysfunction, causing myocardial stress and activation of BNP gene transcription. This hypothesis is suggested by evidence that a larger ischemic burden, and hence a greater volume of myocardium affected, leads to a proportionally higher elevation in BNP [31]. In our study, the severity of CAD taking account of disturbance in usual coronary blood flow did correlate with BNP levels, albeit weakly (Additional file 1: Appendix 9). However, there was no interaction with the association of BNP with adverse clinical events. The impact of hibernating myocardium and the nature of the ischaemic insult itself are confounding issues, further complicated by unapparent or transient left ventricular systolic or diastolic dysfunction [32, 33]. Like other studies, we demonstrate that $\mathrm{BNP}$ is a much more sensitive marker than imaging parameters of systolic dysfunction [29, 34] and also establish that BNP is a risk marker independent of risk modification or incident revascularization. Our BNP cut-point of $100 \mathrm{pg} / \mathrm{mL}$ was pre-specified, but in post hoc analysis was demonstrated as a good inflexion point for an increasing risk of clinical events (Additional file 1: Appendix 10).

Our data would support the use of natriuretic peptides in the routine assessment of not only heart failure patients, but also those under investigation for suspected CAD, even without overt systolic dysfunction. BNP and NT-proBNP are readily available across the world, relatively cheap and can improve both classification and discrimination for longer-term outcomes. At the time of initial patient assessment, identification of patients with subtle elevation in natriuretic peptide levels (BNP > 100 $\mathrm{pg} / \mathrm{mL}$; roughly equivalent to NT-proBNP > $300 \mathrm{pg} / \mathrm{mL}$ ) suggests a high-risk profile. In such patients, it would be reasonable to consider further pharmacological or interventional management, although further research is required to ascertain whether pro-active, intensive therapy would improve prognosis.

\section{Limitations}

As this study was observational, there remain potential biases to consider, including selection for coronary angiography (particularly in patients with known CAD or previous revascularization that are more likely to be offered angiography). BNP levels after CABG are known to be dependent on a number of interacting and variable factors [35]; all analyses were therefore repeated in a cohort excluding prior $C A B G$, and results were identical to those presented. It is also important to note that revascularisation rates were similar, regardless of baseline (blinded) BNP category (Additional file 1: Appendix 3). Although clinicians were blinded to the risk assessments, we cannot exclude the possibility that biomarkers could have been tested in clinical practice during the follow-up period. The lack of heart failure outcomes is a limitation of the study. Assessment of diastolic dysfunction was not a protocol requirement in this study. Post hoc analysis in patients with available data $(n=142)$ showed that mitral inflow E/A ratio $>2$, tissue Doppler $\mathrm{E} / \mathrm{e}^{\prime}$ ratio $\geq 13$ or composite indices of diastolic impairment did not interact with the association of BNP with outcomes ( $p_{\text {interaction }}=0.16$ for death, $p_{\text {interaction }}=0.72$ for composite events).

\section{Conclusions}

In a real-world population, conventional risk factors and other markers of arterial compliance, inflammation and autonomic function had limited value for prediction of long-term outcomes in risk-modified patients assessed for coronary disease. BNP had a strong association with death and cardiovascular events, even without heart 
failure or overt ventricular dysfunction, and independent of revascularisation. BNP $>100 \mathrm{pg} / \mathrm{mL}$ can identify patients with subtle impairment of cardiac function that may conceptually benefit from early, targeted and individualised management to improve prognosis.

\section{Additional files}

Additional file 1: Supplementary methods, tables and figures. (PDF $1127 \mathrm{~kb}$ )

Additional file 2: Plain language summary for patients. (PDF $19 \mathrm{~kb}$ )

\section{Abbreviations}

ACS: Acute coronary syndrome; BNP: B-type natriuretic peptide; CABG: Coronary artery bypass grafting; CAD: Coronary artery disease; Cl: Confidence intervals; CVD: Cardiovascular disease; HR: Hazard ratios; HRV: Heart rate variability; hs-CRP: High-sensitivity C-reactive protein; IQR: Interquartile range; LVEF: Left ventricular ejection fraction; MI: Myocardial infarction; PCl: Percutaneous coronary intervention

\section{Acknowledgements}

This work was only possible with the support of patients and research staff involved in the ARM-CAD study. This work is dedicated to the memory of Philip Poole-Wilson (Imperial College London, UK), Henry Krum (Monash University, Melbourne), and Gishel New (Box Hill Hospital, Melbourne) who were instrumental in setting up the ARM-CAD study. Our thanks to the Alfred Heart Centre, Box Hill Hospital Cardiology Department, the Northern Hospital Catheter Laboratory, Marina Skiba, Guneet Bhambra, Keitaro Senoo, Luke Pickup, Andris Ellims and Will Wilson.

\section{Funding}

The ARM-CAD study was investigator initiated and supported by the Monash Centre of Cardiovascular Research and Education in Therapeutics, Melbourne, and the Royal Brompton \& Harefield NHS Trust Clinical Trials \& Evaluation Unit, London. We received an unrestricted research grant from IM Medical Ltd. Melbourne, who had no involvement with follow-up, data analysis or drafting of results. DK is supported by a National Institute of Health Research (NIHR) Career Development Fellowship (CDF-2015-08-074). The opinions expressed in this paper are those of the authors and do not represent the NIHR or the UK Department of Health.

\section{Availability of data and materials}

The datasets analysed during the current study are available from the corresponding author on reasonable request.

\section{Authors' contributions}

DK led the study group and analysed the patient data. EJ collected patient data. All authors drafted, read and approved the final manuscript.

\section{Ethics approval and consent to participate}

The ARM-CAD Study was approved by Ethics Committees from Monash University, Melbourne, Australia (2006/831MC) and The Alfred Melbourne, Australia (38/07)

All patients provided written informed consent.

\section{Consent for publication}

Not applicable - all original data.

\section{Competing interests}

MDF reports grants from Novartis and personal fees from AstraZeneca, Novartis and Pfizer, all outside the submitted work. DA has received speakers' honoraria from Roche Diagnostics and Siemens Diagnostics, outside the submitted work. PC reports personal speaking honoraria from Menarini, AstraZenica, Bayer, Itamar Medical, Abbott and Ferring Pharmaceuticals, all outside the submitted work. The other authors declare that they have no competing interests.

\section{Publisher's Note}

Springer Nature remains neutral with regard to jurisdictional claims in published maps and institutional affiliations.

\section{Author details}

${ }^{1}$ Institute of Cardiovascular Sciences, University of Birmingham, Birmingham, UK. ${ }^{2}$ Monash Centre of Cardiovascular Research and Education in Therapeutics, School of Public Health and Preventive Medicine, Melbourne, Australia. ${ }^{3}$ Faculty of Medicine and Health Sciences, University of East Anglia, Norwich, UK. ${ }^{4}$ Department of Cardiology, Oslo University Hospital Ulleval, University of Oslo, Oslo, Norway. ${ }^{5}$ Royal Brompton Hospital and National Heart and Lung Institute, Imperial College London, London, UK. ${ }^{6}$ Baker Heart and Diabetes Institute, Melbourne, Australia. 'Faculty of Health Sciences, School of Public Health, Curtin University, Perth, Australia.

Received: 21 December 2018 Accepted: 13 March 2019

Published online: 03 April 2019

\section{References}

1. Wilson PW, D'Agostino RB, Levy D, Belanger AM, Silbershatz H, Kannel WB. Prediction of coronary heart disease using risk factor categories. Circulation. 1998:97:1837-47.

2. Conroy RM, Pyorala K, Fitzgerald AP, Sans S, Menotti A, De Backer G, et al. Estimation of ten-year risk of fatal cardiovascular disease in Europe: the SCORE project. Eur Heart J. 2003;24:987-1003.

3. Kotecha D, Flather M, McGrady M, Pepper J, New G, Krum H, et al. Contemporary predictors of coronary artery disease in patients referred for angiography. Eur J Cardiovasc Prev Rehabil. 2010;17:280-8.

4. Halkin A, Singh M, Nikolsky E, Grines CL, Tcheng JE, Garcia E, et al. Prediction of mortality after primary percutaneous coronary intervention for acute myocardial infarction: the CADILLAC risk score. J Am Coll Cardiol. 2005;45:1397-405

5. Bottle A, Mozid A, Grocott HP, Walters MR, Lees KR, Aylin P, et al. Preoperative risk factors in 10418 patients with prior myocardial infarction and 5241 patients with prior unstable angina undergoing elective coronary artery bypass graft surgery. Br J Anaesth. 2013;111:417-23.

6. Ponikowski P, Voors AA, Anker SD, Bueno H, Cleland JG, Coats AJ, et al. 2016 ESC guidelines for the diagnosis and treatment of acute and chronic heart failure: the task force for the diagnosis and treatment of acute and chronic heart failure of the European Society of Cardiology (ESC) developed with the special contribution of the Heart Failure Association (HFA) of the ESC. Eur Heart J. 2016;37:2129-200.

7. Palazzuoli A, Caputo M, Fineschi M, Navarri R, Calabro A, Cameli M, et al. Btype natriuretic peptide as an independent predictor of coronary disease extension in non-ST elevation coronary syndromes with preserved systolic function. Eur J Prev Cardiol. 2012;19:366-73.

8. Kotecha D, New G, Collins P, Eccleston D, Krum H, Pepper J, et al. Radial artery pulse wave analysis for non-invasive assessment of coronary artery disease. Int J Cardiol. 2013;167:917-24.

9. Kotecha D, New G, Flather MD, Eccleston D, Pepper J, Krum H. Five-minute heart rate variability can predict obstructive angiographic coronary disease. Heart. 2012:98:395-401.

10. Compostella L, Lakusic N, Compostella C, Truong LV, lliceto S, Bellotto F. Does heart rate variability correlate with long-term prognosis in myocardial infarction patients treated by early revascularization? World J Cardiol. 2017;9: 27-38.

11. Yousuf O, Mohanty BD, Martin SS, Joshi PH, Blaha MJ, Nasir K, et al. Highsensitivity C-reactive protein and cardiovascular disease: a resolute belief or an elusive link? J Am Coll Cardiol. 2013:62:397-408.

12. Newson RB. Comparing the predictive powers of survival models using Harrell's C or Somers' D. Stata J. 2004:10:339-58.

13. Sundstrom J, Byberg L, Gedeborg R, Michaelsson K, Berglund L. Useful tests of usefulness of new risk factors: tools for assessing reclassification and discrimination. Scand J Public Health. 2011;39:439-41.

14. Fox KA, Dabbous OH, Goldberg RJ, Pieper KS, Eagle KA, Van de Werf F, et al. Prediction of risk of death and myocardial infarction in the six months after presentation with acute coronary syndrome: prospective multinational observational study (GRACE). BMJ. 2006;333:1091.

15. Williams B, Lacy PS, Thom SM, Cruickshank K, Stanton A, Collier D, et al. Differential impact of blood pressure-lowering drugs on central aortic 
pressure and clinical outcomes: principal results of the Conduit Artery Function Evaluation (CAFE) study. Circulation. 2006;113:1213-25.

16. Roman MJ, Devereux RB, Kizer JR, Lee ET, Galloway JM, Ali T, et al. Central pressure more strongly relates to vascular disease and outcome than does brachial pressure: the Strong Heart Study. Hypertension. 2007;50:197-203.

17. Weber T, Auer J, O'Rourke MF, Kvas E, Lassnig E, Lamm G, et al. Increased arterial wave reflections predict severe cardiovascular events in patients undergoing percutaneous coronary interventions. Eur Heart J. 2005;26:2657-63.

18. Shah NK, Smith SM, Nichols WW, Lo MC, Ashfaq U, Satish P, et al. Carvedilol reduces aortic wave reflection and improves left ventricular/vascular coupling: a comparison with atenolol (CENTRAL study). J Clin Hypertens (Greenwich). 2011;13:917-24.

19. Hillebrand S, Gast KB, de Mutsert R, Swenne CA, Jukema JW, Middeldorp S, et al. Heart rate variability and first cardiovascular event in populations without known cardiovascular disease: meta-analysis and dose-response meta-regression. Europace. 2013;15:742-9.

20. Bigger JT, Fleiss JL, Rolnitzky LM, Steinman RC. The ability of several shortterm measures of RR variability to predict mortality after myocardial infarction. Circulation. 1993;88:927-34.

21. Odemuyiwa O, Malik M, Farrell T, Bashir Y, Poloniecki J, Camm J. Comparison of the predictive characteristics of heart rate variability index and left ventricular ejection fraction for all-cause mortality, arrhythmic events and sudden death after acute myocardial infarction. Am J Cardiol. 1991;68:434-9.

22. Nolan J, Batin PD, Andrews R, Lindsay SJ, Brooksby P, Mullen M, et al. Prospective study of heart rate variability and mortality in chronic heart failure: results of the United Kingdom heart failure evaluation and assessment of risk trial (UK-heart). Circulation. 1998;98:1510-6.

23. Levin ER, Gardner DG, Samson WK. Natriuretic peptides. N Engl J Med. 1998; 339:321-8.

24. von Lueder TG, Kotecha D, Atar D, Hopper I. Neurohormonal blockade in heart failure. Cardiac Fail Rev. 2016;3:19-24.

25. de Lemos JA, Morrow DA, Bentley JH, Omland T, Sabatine MS, McCabe CH, et al. The prognostic value of B-type natriuretic peptide in patients with acute coronary syndromes. N Engl J Med. 2001;345:1014-21.

26. Kragelund C, Gronning B, Kober L, Hildebrandt P, Steffensen R. N-terminal pro-B-type natriuretic peptide and long-term mortality in stable coronary heart disease. N Engl J Med. 2005;352:666-75.

27. Schnabel R, Lubos E, Rupprecht HJ, Espinola-Klein C, Bickel C, Lackner KJ, et al. B-type natriuretic peptide and the risk of cardiovascular events and death in patients with stable angina: results from the AtheroGene study. J Am Coll Cardiol. 2006;47:552-8.

28. Di Angelantonio E, Chowdhury R, Sarwar N, Ray KK, Gobin R, Saleheen D, et al. B-type natriuretic peptides and cardiovascular risk: systematic review and meta-analysis of 40 prospective studies. Circulation. 2009;120:2177-87.

29. Jernberg $T$, James $S$, Lindahl $B$, Johnston $N$, Stridsberg $M$, Venge $P$, et al. Natriuretic peptides in unstable coronary artery disease. Eur Heart J. 2004;25: 1486-93.

30. McKie PM, Cataliotti A, Lahr BD, Martin FL, Redfield MM, Bailey KR, et al. The prognostic value of $\mathrm{N}$-terminal pro-B-type natriuretic peptide for death and cardiovascular events in healthy normal and stage $A / B$ heart failure subjects. J Am Coll Cardiol. 2010;55:2140-7.

31. Sabatine MS, Morrow DA, de Lemos JA, Omland T, Desai MY, Tanasijevic M, et al. Acute changes in circulating natriuretic peptide levels in relation to myocardial ischemia. J Am Coll Cardiol. 2004;44:1988-95.

32. Palazzuoli A, Poldermans D, Capobianco S, Giannotti G, lovine F, Campagna $M S$, et al. Rise and fall of B-type natriuretic peptide levels in patients with coronary artery disease and normal left ventricular function after cardiac revascularization. Coron Artery Dis. 2006;17:419-23.

33. Redfors B, Chen S, Crowley A, Ben-Yehuda O, Gersh BJ, Lembo NJ, et al. Btype natriuretic peptide assessment in patients undergoing revascularization for left main coronary artery disease. Circulation. 2018;138:469-78.

34. Richards M, Nicholls MG, Espiner EA, Lainchbury JG, Troughton RW, Elliott J, et al. Comparison of B-type natriuretic peptides for assessment of cardiac function and prognosis in stable ischemic heart disease. J Am Coll Cardiol. 2006; $47: 52-60$

35. Berendes E, Schmidt C, Van Aken H, Hartlage MG, Rothenburger M, Wirtz S, et al. A-type and B-type natriuretic peptides in cardiac surgical procedures. Anesth Analg. 2004;98:11-9.

\section{Ready to submit your research? Choose BMC and benefit from:}

- fast, convenient online submission

- thorough peer review by experienced researchers in your field

- rapid publication on acceptance

- support for research data, including large and complex data types

- gold Open Access which fosters wider collaboration and increased citations

- maximum visibility for your research: over $100 \mathrm{M}$ website views per year

At BMC, research is always in progress.

Learn more biomedcentral.com/submissions 